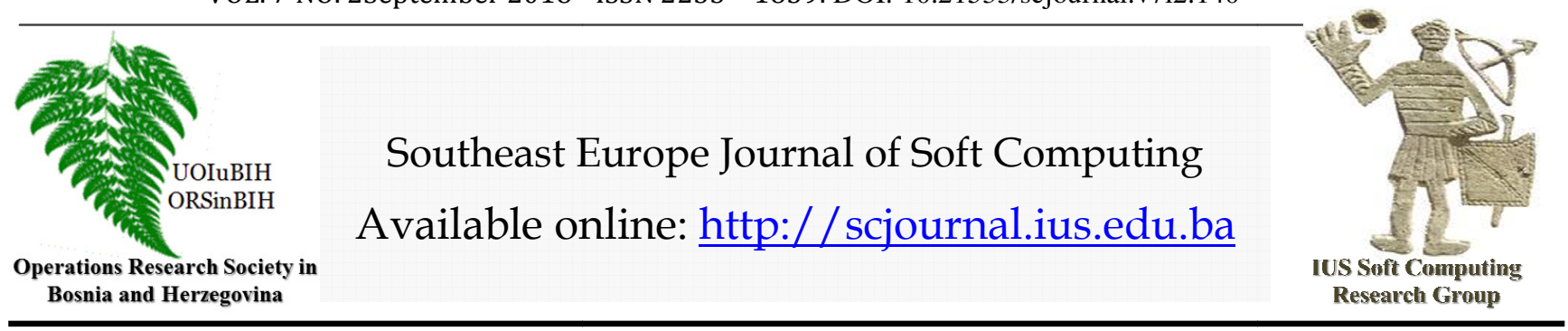

\title{
Risk Exposition of Prices in Agricultural Commodities Using Options and Futures
}

\section{J. Karabegović}

Faculty of Business and Administration, International University of Sarajevo International University of Sarajevo, HrasnickaCesta 15, Ilidža 71210 Sarajevo, Bosnia and Herzegovina jasminakarabegovic95@hotmail.com

\section{Article Info}

\section{Article history:}

Article received on 18 June 2018

Received in revised form 27 August 2018

Keywords:

options, futures, GARCH $(1,1)$, implied volatility, financial derivatives

\begin{abstract}
Changes and fluctuations in commodity prices exert different effects on value chain participants, depending on the position they have in the chain. Agricultural commodities are exposed to a set of different factors influencing the prices of the commodities. They are influenced by the season, weather shocks, demand and supply forces, household income, tastes and preferences of the consumers. Observing the most recent history, high price fluctuations have been observed during the financial crisis in 2008. One out of many approaches for hedging the price risk is the usage of financial derivatives. This study will be concerned with the volatility modelling methods with the help of futures and options for corn and soya. Methods used for modelling the volatility are GARCH and Black Scholes Implied Volatility. The simplest method in ARCH family, namely the GARCH $(1,1)$ method will be used for modelling volatility based on the historical futures data dating back to 2005. The implied volatility is derived solving back the Black - Scholes Model, only this time looking for sigma. The sole purpose of the thesis is to examine which of the two methods has a better predictive power. Model comparison is done with the help of forecast regression models. The regression models have shown the difficulty in assessing which model has more accurate predictive power. The Adjusted R2 for both models in both cases is relatively low. However, the GARCH $(1,1)$ model has slightly higher values for this indicator. Even the GARCH $(1,1)$ model has shown a better performance, due to the relatively low adjusted R2 values, no stable conclusion regarding the model performance can be derived.
\end{abstract}

\section{INTRODUCTION}

Derivative is a financial instrument that has a value depending on or derived from prices of underlying
assets(Hull, 2008). Options are financial instruments in the form of a contract that are traded between the writer of an option and an option holder, and it provides the 
contract holder to buy or sell the option at a strike price on exercise date either in the OTC market or on an exchange (Hull, 2008). It is possible to place an option on everything that can be traded, including grains, oil, metals, futures contracts, currencies. They are used as tools for hedging, arbitraging, and speculating, and therefore need to be properly priced.

\section{OPTIONS, FUTURES AND OTHER DERIVATIVES}

Two types of options exist: call option and put option. A call option provides the holder with the right to buy an asset at the exercise price on expiration date, whereas the put option provides the holder with the right to sell an asset at the exercise price on expiration date (Hull, 2008).

\subsection{Options}

A call option is a bullish instrument because increase in the price of the underlying security is expected, whereas the put option is a bearish instrument and the decrease of the underlying security is expected (Cohen, 2005). Another classification of options can be on American and European options. This category is not based on the geographical area on which they are traded, but rather on the time at which they can be exercised. American options can be exercised at any time before the maturity date, unlike European options that can be exercised only at the maturity date. (Hull J. C., Options, Futures, and Other Derivatives, 2008) Two parties are involved in placing and option: the writer and the buyer of the option. The writer is an individual who creates and option and has to fulfill the legally binding obligation, and the buyer is the party that holds the option and obtain rights to either exercise it or not, unlike the futures contracts (Hull, 2008). Investing in options has both its advantages and drawbacks. One advantage is the leverage they give to the option holder. The option holder can lose only the amount of money that is invested in the option (in the worst case). On the other hand, profits might be quite high depending on whether the price of the underlying security are going up or down. A drawback of these contracts is that the holder has no right on dividends nor ownership. (Gitman \& Joehnk, 2008)

As already mentioned, the parties involved in option issuance are the buyer and the writer. The buyer of the option takes long position, whereas the seller takes the short position. According to that, option trading can have four positions: Long Call, Long Put, Short Call, Short Put (Hull J. C., Options, Futures, and Other Derivatives, 2008). As can be concluded from Table 1 by purchasing an option, the buyer acquires certain rights that he or she does not have to exercise, whereas the seller (or the writer of an option) has to exercise those rights.
Table 1: Options Positions

\begin{tabular}{|l|l|l|}
\hline & Buyer (long) & Seller (short) \\
\hline Call & Right to buy & Obligation to sell \\
\hline Put & Right to sell & Obligation to buy \\
\hline
\end{tabular}

According to Cohen (2005), the investors are seeking to increase the value of the option, investors will buy put and call options that have at least three months left until the expiration date, and in that way, try to meet their expectations (Cohen, 2005). Option price is comprised of two parts: strike price and fundamental value.The strike price or exercise price is a contract price at which the option can be exercised. Fundamental or intrinsic value is the difference between the spot price and strike price. The fundamental value for call options is calculated as in Equation (1):

$$
\begin{aligned}
& \text { Fundamental Value of a Call } \\
& =\text { (Market price of the underlying asset } \\
& \text { - Strike price on the call) }
\end{aligned}
$$

Simply said, the fundamental value of a call is the difference between the market price of the underlying asset and the strike price on the call. In the Table 2 it is summarized when a call option is at the money, in the money, and out of the money.

Table 2: Call Options

\begin{tabular}{|l|l|}
\hline In the money & Strike Price $<$ Spot Price \\
\hline At the money & Strike Price $=$ Spot Price \\
\hline Out of the money & Strike Price $>$ Spot Price \\
\hline
\end{tabular}

Put options are not valued in the same way as call options, and their fundamental value is calculated according to Girman \& Joehnk (Girman \& Joehnk 2008) as shown in Equation (2):

Fundamental Value of a Put

$=$ Strike Price on the put - Market price of underlying assets.

In Table 3 it can be seen when a put is in the money, at the money and out of the money.

\section{Table 3: Put Options}

\begin{tabular}{|l|l|}
\hline In the money & Strike Price $>$ Spot Price \\
\hline At the money & Strike Price $=$ Spot Price \\
\hline Out of the money & Strike Price $<$ Spot Price \\
\hline
\end{tabular}

Options are never sold at their fundamental or intrinsic valuebut at the premium price. The premium price is the price the buyer pays in order to obtain the rights to buy or sell certain amount of underlying securities, whereas the seller of the option views it as a compensation for issuing 
the option and having certain obligations to fulfil. The seller keeps the premium regardless of whether the option is exercised or not. (Gitman \& Joehnk, Chapter 14: Derivatives Securities, 2008)

Special type of options mostly used for agricultural commodities (such as corn, soybeans, cotton, crude oil, natural gas, gold and others) are options on futures contracts. The name alone implies that the underlying asset is the futures contract, and at the expiration date of the option, the futures contract is delivered. As with other types of options, the holder obtains the right, but not the obligation to enter into a futures contract at a certain price in the future. If the call futures option is exercised, the holder of the option receives long futures position together with the cash from the excess of the futures contract over the strike price, and vice versa holds if a put option is exercised. The underlying futures contract has later expiration date than the option contract. Futures contract in the role of the underlying asset has the same behavior pattern as the stock with dividend yields, and this is accomplished by setting the stock price equal to the risk futures price, and the dividend yield equal to the risk-free rate. Usually these options are American type of options. One of the main reason for the usage of this type of options is because of its high liquidity. Another reason is due to the fact that the futures price is immediately known, unlike the spot price of the underlying asset. The reason why it is so popular in the agricultural sector is for the trading convenience. (Hull J. , Futures Options, 2008)

\subsection{Futures}

Futures are another derivative instrument used for hedging the risk of price fluctuations. Futures are standardized forward contracts between two parties at a predetermined price at a specified time in the future. Futures contracts are traded at exchanges around the world, including CBOT, CME, NYME, NYSE Euronext, EUREX, BM\&F BOVESPA. As is the case with the options, the buyer of the futures contract takes long position, whereas the seller of the futures contract takes short position. In most of the cases in trading with futures, the investors are engaging into closing out position. Closing out a position means entering an opposite trade to the original one.(Gitman \& Joehnk, Commodities and Financial Futures, 2008)

All futures quotes can be obtained from exchanges. Prices are comprised of Opening price, highest price and lowest price. The Closing price is the settlement price which is used for calculating daily gains and losses and adjusting the margin requirements. Trading volume and open interest data can also be withdrawn from exchanges. (Futures options, 2008)

Futures prices create trading patterns, or trends. Depending on the underlying asset and commodity traded, the futures prices may have different behaviors as the maturity day approaches. In case of gold, the futures prices usually increase with the maturity of the contract. Markets where the futures prices rise as the maturity of the contract approaches are known as normal markets, whereas the markets with decreasing futures prices are known as inverted markets. A specific case is with agricultural commodities, where the prices of the futures might have mixed patterns caused by both increase and decrease of the prices depending on the season.(Futures Contracts, 2011)

The contract delivery period is appointed by the exchange. The decision of the place of delivery is made by the seller of the contract, where the seller issues the notice of intention to deliver to the exchange clearing house. The exchange finds the party that will accept the delivery. The reason for this is that the primary holder of the contract might not be the party which will take the delivery, since it is already mentioned that the long position holders usually go closing out the position. The notice of intention to deliver is comprised of information regarding the quantity of contracts to be delivered, and in cases of commodities, what grade of commodities will be delivered. The exchange matches the short and long position holders to deliver the contract. Futures contracts have three critical days:

1. First notice day - represents the first day at which the notice of intention can be submitted to the exchange

2. Last notice day - represents the last day at which the notice of intention can be submitted to the exchange

3. Last trading day - represent the last couple of days before the last notice day.(Gitman \& Joehnk, Commodities and Financial Futures, 2008)

There are two main types of traders:

1. Futures commission merchants

2. Locals.

FCM are given instructions by their clients and they follow and charge commission for executing orders, whereas the locals doing trade on their own account. A market order is an order to buy or sell with a broker immediately and with the best current market price. Other forms of orders also exist:

A limit order - is an order to buy or sell at a specified price. Depending on whether buying or selling order should be delivered, a buy limit order can be executed at the limit price or below it, and vice versa stands for the selling order.

Stop order or stop-loss is an order to buy or sell as soon as the specified price has been reached, which is also known as the stop price and becomes a market order.

Stop - limit order - combines stop and limit orders. When the specified price is reached, it becomes the stop price. After this price is reached, the stop limit order becomes the limit order. 
Market if touched order- is executed at the best available price, meaning that an order to buy or sell are executed when the instruments price is below or above the market price. The main idea of this order is to take advantage of unexpected fluctuations in prices of underlying assets.

Discretionary order or market - not - held order is a special type of order offered by certain exchanges. It is traded as a market order, but may be postponed if the broker expects a better price in the future.

A time of day ordersspecifies a particular period of time during which the buying or selling order can be executed.

An open order or a good till cancelled is an order to buy or sell that is in effect until the trading of the contract is executed at the specified price. A fill or kill order is a special type of order where the buy or sell must be executed immediately, or not at all. (Hull J. , Futures Options, 2008)

\section{Table 4: Futures attributes summarized}

\begin{tabular}{|l|}
\hline Traded on an exchange \\
\hline Standardized contract \\
\hline Range of delivery dates \\
\hline Settle daily \\
\hline Contract is usually closed out prior to maturity \\
\hline Virtually no credit risk \\
\hline
\end{tabular}

Source (Options, Futures and Other Derivatives, $8^{\text {th }}$ edition, John C. Hall, chapter 3, pg. 41)

Economists define price volatility as the standard deviation of logarithmic prices (Gilbert \& Morgan).Main causes of price volatility are changes in production and production costs, consumer behavior, stockholding. The production depends on the fields that have been planted as well as weather shocks. The consumer behavior is mostly determined by the changes in income of an individual, and changes in prices of commodities which force the consumers to switch to substitutes. Stockholdings of grains were low in 2006, which resulted in high price volatility of grains. Period needed to recover the stockholdings might last for years. These shocks might be correlated, and may harm also non-agricultural markets. (Gilbert \& Morgan) Prices of agricultural commodities are adjusted seasonally, which is not a characteristic of other financial instruments (Dharmawan, 2017).

The importance of derivatives in agricultural commodities has enlarged in the last two decades, since the volume and variety of agricultural commodities traded on the market has increased (Dharmawan, 2017),(Hull J. C., Options, Futures, and Other Derivatives, 2008).

This research is concerned with modelling the volatility. Two approaches for that will be used, namely the GARCH $(1,1)$ model and the Black - Scholes Implied Volatility Model. The purpose of the study is to examine which model has a better and more accurate predictive power.
Data used for the purpose of conducting the research has been obtained from two exchanges, CBOT and CME. The futures data, as underlying assets, is in time interval between 01/01/2005 until 01/04/2018. The options on futures data is in time interval between 01/01/2013 until $01 / 04 / 2018$. The hypothesis is that the $\operatorname{GARCH}(1,1)$ has a better predictive power compared to the Black - Scholes Implied Volatility Model.

\section{METHODOLOGY}

Finance is a really dynamic and one of the most changing areas in the corporate business world. A popular topic among the researchers is the option valuation. For decades attempts existed to create the proper model for valuation. In 1960s many mathematicians such as Sprenkle (1961), Ayes (1963), Samuelson (1965), Boness(1964), Chen (1970) and others tried to create option valuation model. They expressed their work based on the warrants valuation, and generated the same formulas for option valuation, but still something was missing.

\subsection{Black - Scholes - Merton Model}

Published in 1973, "The Pricing of Options and Corporate Liabilities" by Fischer Black and Myron Scholes, new and original model for options pricing has been introduced. They transformed the option pricing model into partial differential equations with variable coefficients. The idea was about constructing the riskless portfolio taking positions in bonds (cash), option, and underlying stock. (A.S.Shinde \& K.C.Takale, 2012).

According to Fischer Black and Myron Scholes (Black \& Scholes, 1973), Scholes and Merton Their assumption was that "ideal conditions" existed on the market, and their option was derived from the value of the stock as an underlying asset:

1. Constant short-term interest rate over time

2. Stock price follows a random walk, and the variance of the variance rate is proportional to the square of the stock price

3. The stock does not pay dividends

4. Only European options are taken into consideration

5. There are no transaction costs involved in buying or selling them

6. No penalties on short selling

7. At the short-term, interest rate it is possible to borrow any fraction of the price.

Variables that this model includes are:

1. Exercise or strike price of the option

2. Time remaining until expiration date

3. Current price of the stock or any other underlying asset

4. Interest rate over the life of the option 
5. Volatility of the underlying asset price - it is considered to be even the most important variable, since the changes in the volatility might influence the option's value.

Assumptions regarding constant volatility and risk-free interest rate can be relaxed and transferred to becoming the function of time.(The Black - Scholes - Merton Model, 2008)

If all the assumptions hold, the value of the option will be expressed as a function of time and the price of the underlying security or $\mathrm{V}(S, t)$. Using the generalized Weiner process, the stock price behavior in the real world situations can be explained as in Equation 3:

$$
d S=\mu S d t+\sigma S d w
$$

This equation tells that the return is randomly distributed (the returns are random walk), where $\mu$ denotes the expected rate of return, and $\sigma$ represents the volatility. Using the Ito's Lemmamathematical identity,it is attemptedto price the expected value. The following equation can be written:

$$
d V=\frac{\delta V}{\delta S} d S+\frac{\delta V}{\delta t} d t+\frac{1}{2} * \frac{\delta^{2} V}{\delta S^{2}}(d S)^{2}
$$

And it represents the change in the price as the stock moves. If Equation 3 is implemented into Equation 4, Equation 5 is obtained:

$d V=\frac{\delta V}{\delta S} S *(\mu d t+\sigma d w)+\delta \mathrm{V} / \delta \mathrm{t} * \mathrm{dt}+\mathrm{S}^{\wedge} 2 * \sigma^{\wedge} 2 * \mathrm{dt}$

Next step is to eliminate randomness $(\sigma d w)$ by creating a portfolio which will be an option and a share of a stock. If randomness (Wiener process) is eliminated, it is clear that the portfolio will earn a risk - free rate. In other words, it will behave like cash. The elimination of randomness will follow Equation (6), and the value of the portfolio is:

$$
V-\frac{\delta V}{\delta S} * S
$$

Now, the value of the option is calculated. $S$ is known, the coefficient $\frac{\delta V}{\delta S}$ is a constant number. The change in the portfolio is calculated as:

$$
d V-\frac{\delta V}{\delta S} * d S
$$

Basically, it represents the sensitivity of the option price to the movement of the stock.

Implementing the above formulas, Equation (8) can be derived

$$
\begin{aligned}
\frac{\delta V}{\delta S} S * \mu d t+\frac{\delta V}{\delta S} & * S * \delta * d w+\frac{\delta V}{\delta t} * d t+S^{2} * \sigma^{2} * d t \\
& -\frac{\delta V}{\delta S} * S * \mu-\frac{\delta V}{\delta S} * S * \sigma \\
& * d w
\end{aligned}
$$

The risk-free rate will be the part of the risk neutral form, and can be expressed as follows:

After solving the Equation (7), the Equation (8) is obtained which represents the risk-neutral form of the portfolio:

$$
\frac{\delta V}{\delta t} d t+S^{2} * \sigma^{2} * d t(9)
$$

This means that the portfolio is earning the risk-free rate, which is shown in Equation (10):

$$
\frac{\delta V}{\delta t} d t+S^{2} * \sigma^{2} * d t=r *\left(V-\frac{\delta V}{\delta S} * S\right) d t(10)
$$

Solving the Equation (10), the Black Scholes Formula is obtained in Equation (11):

$$
\frac{\delta V}{\delta t}+\frac{1}{2} * S^{2} * \sigma^{2}+\frac{\delta V}{\delta S} * S-r V=0(11)
$$

Solving the differential equation (10), the equation (11) for the call options can be obtained:

$$
c=S N(d 1)-K e^{-r T} N(d 2)
$$

Where $\mathrm{S}$ is the current stock price, $\mathrm{K}$ is the option exercise price, $\mathrm{T}$ is the time to expiration date, and $\mathrm{r}$ is the risk-free rate, $\mathrm{N}$ is the cumulative normal distribution, and $\mathrm{e}=$ 2,7183 .

Additionally, values for $\mathrm{d} 1$ and $\mathrm{d} 2$ can be provided in equations (13) and (14), where $s$ represents standard deviation of stock returns, and inserting them into equation (12) the European call option price can be calculated:

$$
\begin{array}{r}
d 1=\frac{\ln \left(\frac{s}{K}\right)+\left(r+\frac{\sigma^{2}}{2}\right) * t}{s} * \sqrt{t}(13) \\
d 2=\frac{\ln \left(\frac{s}{K}\right)+\left(r-\frac{\sigma^{2}}{2}\right) * t}{s} * \sqrt{t}(14)
\end{array}
$$

Besides the popularity of this model used in the calculations of options' prices and its pros, also cons exist. One of them is that the assumption of constant risk-free rate of return and volatility are not true in real life. All of them can change over time with high variance, and this might cause the fluctuation of option price. Even the variances are not high, high frequencies can cause problems. Next, the liquidity risks are ignored and the assumption about costless trading is made. Assumption that stock prices show lognormal returns, are not correct. In the real world, the distributions are skewed, and the options might be either overpriced or underprized. The model assumes that no dividends are paid out, which further leaves an impact on the valuation process. It is only applicable to European Options, which can be exercised at the expiration, and is unsuitable for American Options since American Options have a more flexible rule when it comes to exercising the option. The reasons why this model is often used is that they are a popular method for non-dividend paying stocks used for delta hedging strategy. (Yalincak, 2012) 


\subsection{Implied Volatility Model}

One of the drawbacks of the Black-Scholes model is one of its assumptions about the constant instantaneous mean and volatility. Even the application of this model is high, it has some controversies in a sense that future volatilities (forecasts) need to be made based on the constant past volatility. However, the asset prices are characterized with high kurtosis and skewness, which means that the changes in risk move much faster and frequently than the Gaussian distribution anticipates. Therefore, more rational investors deal with models that take into account data with stochastic volatilities. Two possibilities for prediction of future market prices exist: to calculate the realized volatility from the historical data (GARCH model covered in the next section) or to calculate the implied volatility from the current option prices. These models require the prediction of entire joint probability distribution for asset returns and are much more complicated than models with constant volatilities. (Canina \& Figlewski, The Informtional Content of Implied Volatility, 1993)

Implied volatility model is a parameters part of the options pricing model, which is analyzing past behaviors and based on these patterns predicts the future situation on the market (Dumas, Fleming, \& Whaley, 1998). Implied volatility is an increasing function when the historical volatilities are low, and vice versa (Volatility Smiles, 2008). The implied volatility is an unobserved part of the BSM model. To obtain the implied volatility, following inputs should be available:

1. The market price of the option

2. The price of the underlying security

3. The strike price,

4. Time to expiration

5. The risk-free interest rate.

Implied volatility is calculated by inserting the market price of the option into the Black Scholes model and back solving it to get the value of implied volatility (Athanasios Trianfyllou, 2013).

\subsection{Newton - Raphson model}

To calculate the Black - Scholes Model backwards, some numerical approaches should be taken into consideration, which is in this case the Newton - Raphson Model. This is an efficient way for finding roots. It is an approximation method that uses analytic derivative to make estimations about where the solution can be found. The approximation that starts with an initial guess can be improved with the formula shown in Equation (15):

$$
\sigma n+1=\sigma n-\frac{f(\sigma n)}{f \prime(\sigma n)}
$$

The model and the market value of the option should not have significant differences, or in other words, the model value should be as accurate as possible to the market value. (YPMAt, 1995)

This can be expressed as Equation (16):

$$
\mid V \text { market }-V \text { model } \mid<\epsilon
$$

The Black - Scholes Equation can be expressed as the function of $\mathrm{x}$, as in Equation (17):

$$
f(x)=\text { Vmodel }=f(\sigma)=B S(\sigma)
$$

The derivative of the Equation (17) is called vega, and can be expressed as shown in Equation (18):

$$
f^{\prime}(\sigma)=\frac{\Delta f(\sigma)}{\Delta \sigma}
$$

Vega is the measurement for changes in option prices relative to the $1 \%$ change in the volatility. (Cui, Rollin, \& Germano, 2016)

$$
\operatorname{Var}\left(x_{t} \mid x_{t-1}, x_{t-2}, \ldots\right)=\sigma_{\mathrm{w}}{ }^{2}(19)
$$

Understanding the concept of volatility is from crucial importance since it is one of the key factors for price risk management, and making decisions based on observed price data $\mathrm{Pt}$ at certain time. The aim of GARCH is to model the return or growth of a series, so the return of an asset at time $t$ with price Xt can be written as

$$
r t=\frac{x t-x t-1}{x t-1}(20)
$$

Assuming that there are $\mathrm{r} 1, \mathrm{r} 2, \ldots . \mathrm{rn}$ returns and that these returns are normally distributed

$$
\mathrm{rt} \sim \mathrm{N}\left(0, \sigma^{2}\right)(21)
$$

0 is the average expected value of $\mathrm{rt}$ and the variance is $\sigma_{\mathrm{t}}^{2}$. The variance of the model is written as:

$$
\text { Var }=\left(r 1^{2}+r 2^{2}+\ldots . r 3^{2}\right) / n(22)
$$

Or written in a different form as:

$$
\begin{array}{r}
\sigma^{2}=\alpha 1 * r 1^{2}+\alpha 2 * r 2^{2}+\cdots \alpha n * r n^{2}(23) \\
\text { where } \\
\alpha n=\frac{1}{n}(24)
\end{array}
$$

In that case, the simplest GARCH model with equally weighted periods can be written as:

$$
\frac{1}{n} *\left(\varepsilon 1^{2}+\varepsilon 2^{2}+\cdots+\varepsilon n^{2}\right)
$$

The $\alpha i$ can be assigned to different weights. If $\alpha$ gets different values, then the simplest GARCH $(1,1)$ model can be written as:

$$
\sigma^{2}=\alpha 1 * \sigma^{2}(t-1)+\beta 1 * r^{2}(t-1)(26)
$$

Where $\alpha 1+\beta 1<1, \alpha 1>0, \beta 1>0$ or the model is unstable. (yaacov kopeliovich, n.d.)

The sum of $\alpha i$ weights should be equal to 1 . To extend this idea, it is possible to include the long-run average variance 
rate and assign some weight to it. This model can be written in the following form:

$$
\sigma^{2} t=\gamma V L+\alpha u^{2} t-1+\beta \sigma^{2} t-1
$$

Where VL represents the included long - run variance and the $\gamma$ is the weight assigned to it. The sum of $\alpha, \beta, \gamma$ must be equal to 1. (Hull J. , Estimating Volatilities and Correlations, 2008)

This formula tells that the conditional variance of $\sigma^{2}$ at time $t$ depends on both squared error terms and conditional variance in the previous period. $\operatorname{GARCH}(p, q)$ is a generalized model where $\mathrm{p}$ represents lagged terms of the squared error term and $\mathrm{q}$ terms of the lagged conditional variances. (Time Series Econometrics: Forecasting, 2004).

There are ways to test how good the model is. The assumption of the model is that the variance changes as time passes, which means that there are periods with extremely high volatility, whereas in the other the volatility is relatively low. One way to test the model is by examining the autocorrelation between $u^{2}$ and $\sigma^{2}$. If the autocorrelation is low, the model is good. Testing the autocorrelation can also be done by implementing the Ljung - Box statistics. The GARCH $(1,1)$ model can be used to make estimations about the volatility term structure, and these estimations can be used to forecast the actual volatility structure. (Hull J. , Estimating Volatilities and Correlations, 2008)

Some drawbacks of the model are related to the assumption that both positive and negative effects have the same impacted since both values taken are squared. Another drawback is that the parameters are tightly constrained. The models are more likely to over predict the volatility because the response to highly isolated returns is slow. (Robert H. Shumway; David S. Stoffer, 2016).

\section{LITERATURE REVIEW}

Even the idea of options existed in the time of Aristotle, trading options started in $17^{\text {th }}$ century in the United States (Gitman \& Joehnk, 2008).Derivatives exchange markets exist for a very long time, dating back to 1848 when The Chicago Board of Trade has been established with the primary purpose to determine the standardized quantities of traded grains (Hull J. C., Options, Futures, and Other Derivatives, 2008).

\subsection{Historical Background}

The call options were traded in 1973, and in 1977 the put options entered the market as well (Hull J. C., Options, Futures, and Other Derivatives, 2008). 1970s and 1980s have been characterized with higher price volatilities in agricultural commodities (Gilbert \& Morgan). The period between 2006 and 2013 had many ups and downs in prices of agricultural commodities. The first rapid price increases in agricultural commodities characterized the period between September 2006 and February 2008 (Triantafyllou, Dotsis, \& Sarris, Volatility Forecasting in Agricultural Commoidity Markets, 2013). This period is known as the "2008 price spike"(Gilbert \& Morgan), in which the prices were pushed up to $70 \%$ of the nominal dollar value on average, and it resulted in the price increase of other related commodities to even higher levels(Triantafyllou, Dotsis, \& Sarris, Volatility Forecasting in Agricultural Commoidity Markets, 2013). The prices went down in the second half of 2008, but they were still above the price level before the price spike. In 2010 the prices rose sharply again, but calmed during 2011 and 2012. However, 2013 experienced a new rise in prices. These fluctuations increased the risk of all market stakeholders. The concerns were especially about the effects on the poor countries which depend more on imported food and staple food, but also about the exporters whose profits and sales plans might be adversely affected (Triantafyllou, Dotsis, \& Sarris, Volatility Forecasting in Agricultural Commoidity Markets, 2013)

\subsection{Volatility}

Three main issues the volatility forecasts resolve is asset allocation, risk management strategies, and taking bets on future volatilities. Volatility forecasts are mostly used in options trading, so the investors and traders for developing the trading strategy.(Reider, 2009)

Many agricultural commodities, especially grains, are an input for processed food. High volatility in such prices is a major concern for the economy of every country, creating major import bill uncertainty accompanied with the exchange rate uncertainty. (Gilbert \& Morgan, 2010)Empirical evidence shows that futures agricultural prices have unexpected jumps and declines of prices. These can be explained by seasonal and maturity effects. "Samuelson hypothesis" (P.A., 1965) states that the volatility increases as the day to maturity approaches. Seasonal harvest of crops is accompanied with volatilities in futures prices. Researchers such Galloway and Kolb (W. \& R.W., 1996)supported the maturity effect in their work. Anderson (R.W, 1985) also confirmed the maturity effect, but his work proved that the maturity effect has less power than seasonality. Empirical evidence has shown that the GARCH option pricing model outperforms the Blacks Scholes model. (Lien, 2002) However, different estimation models can lead into different directions. The causes for that might depend on the data and the time period taken for these data. One example of that is illustrated in the work of Parakash (2011b). The data used for the analysis were cereals, and the observed period was longer than forty years. The volatility forecasts showed a mild upward trend. On the other hand, implied volatility model applied on the same data set showed a sharp upwards trend 
(Triantafyllou, Dotsis, \& Sarris, Volatility Forecasting in Agricultural Commodity Markets, 2013), (A., Safeguarding food security in volatile global markets).

Research conducted by Giot (2003) on prices of cocoa, sugar, and coffee future contracts, the implied volatility derived from the Black - Scholes formula delivered better results than GARCH model (P, 2003).

These volatility models can be also applied into other sectors beyond the agricultural sector. Canina and Figlewski (1993) applied the implied volatility model and historical volatility models on OEX index. Despite that the implied volatility model has proven itself to be a very good estimate of the future volatility, they disagree. This does not hold only for the implied volatility models, but also for the historical volatility models. (Canina \& Figlewski, The Informational Content of Implied Volatility, 1993)

Another interesting case where the model has been applied is the forecast of hourly prices in the deregulated electricity markets of Spain and California. GARCH and ARMA model have been compared and the results have shown the advantages of the GARCH model (Garcia, et al., 2005)

\section{DATA}

It is usually stated that more frequent data the better. It is also more favorable to use trading day's data than the whole week, since there are not many changes in trading during the weekend or periods of calm. The life of an option is usually measured using trading days rather than calendar days. Due to data access limitations, this research will be provided with monthly data only. Despite the obstacles created by limited access to the data, several assumptions have been made in order to make the applicability of the models easier.

\subsection{Options Data}

Two types of data are used for conducting this research. The first data type are options, particularly options on futures contracts. One beautiful explanation for this exists: futures contracts have standardized quantities for delivering the agricultural commodities, and for that reason the futures contracts are used as underlying securities for the options. The options data are obtained from the Chicago Mercantile Exchange (CME), and the sample period is from 01/01/2013 till 01/04/2018 supplied by CME, with monthly frequency. The sample size is contained from 60 observations. The data for interest rates consists of daily 90-day rates and yields of Certificates of Deposits obtained from FRED ${ }^{1}$. The importance for the usage of options data is to estimate the implied volatilities

\footnotetext{
${ }^{1}$ https://fred.stlouisfed.org/series/IR3TCD01USM156N
}

by applying the Black - Scholes Implied Volatility Model. Even the options on futures are usually American options, several assumptions will be applied on them so the Black Scholes Merton model can be applicable. Namely, the first assumption is that the American option will adopt one characteristic of European options, and this is that it will not be exercised before the expiration date. The second assumption will be that the options will be traded at the money.

\subsection{Futures Data}

The futures data for agricultural commodities consist from daily futures prices of corn (ZC) and soya (ZS) adopted from Chicago Mercantile Exchange (CME). The sample period for data analysis is twelve years, more precisely from 01/01/2005 till 31/12/2017. The sample size is contained from 4,380 observations. The sample period covers even one highly volatile time interval and this is the global crisis 2006-2013 (even the volatility in their periods started in 2006). The prices of the commodities (soya and corn) have been obtained from FRED, and will be used as spot prices. The sample period is from 01/01/2005 till 01/01/2018.

\section{DISCUSSION}

This part of the paper will be concerned with the results that have been obtained by processing the data. Data was processed with the help of RStudio. Packages activated for data processing were "rugarch", "parallel", "tseries", "zoo", forecast", "FinTS", "quantmod". The first model to be analysed is the historical volatility based model, the GARCH $(1,1)$ model.

Since the analysed data set is time series related data, the zoo package will be from great help in analysing it. The first step is to see if ARCH model is present in the data. In other words, it has to be checked if the variance is changing across different points of time, which is the main objective of ARCH effect. Firstly, a plot has to be made of the daily prices of the corn futures prices which can be seen in Figure 1:

\section{Daily Returns}

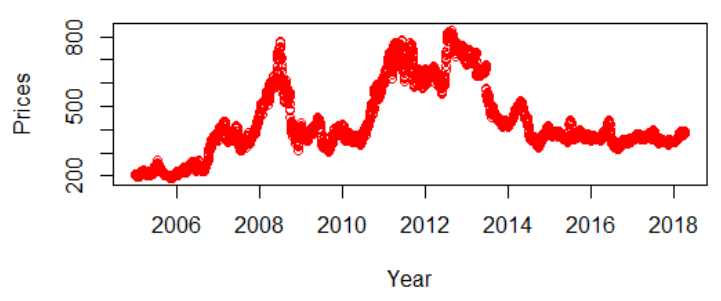

Figure 1: Plot of Corn Futures Prices 
The graph confirms the already known fact that the prices in period between 2006 and 2008 are showing a high volatility caused by the world crisis. Again, in period between 2012 and 2014 high fluctuations have been noticed, and after 2015, the prices calmed. The figure itself is telling that the volatility is not constant over time and that the ARCH effect is present. However, to prove the ARCH effect, Ljung Box test has been used. The Ljung Box test is used for testing the autocorrelation in the squared returns. The null hypothesis of the Ljung - Box test is that there is not an autocorrelation between the returns. By running the Ljung - Box test in $\mathrm{R}$, the following results have been obtained:

Table 5: Ljung - Box test results

Box-Ljung test

data: core data(corn_f)

$\mathrm{X}$-squared $=901220, \mathrm{df}=360, \mathrm{p}$-value $<2.2 \mathrm{e}-16$

As it can be seen from the table, the $\mathrm{p}$ - value obtained is much lower than the significance level

$\alpha=0.05$. This indicates that the null hypothesis has been rejected, and that autocorrelation exists between squared returns. To check the accuracy of that test, the Lagrange Multiplier (LM) test. The LM test will be conducted with the help of FinTS package, and the function ARCHtest. In Table 6, the results of the LM test can be seen:

Table 6: Lagrange Multiplier Test for Testing the ARCH Effects

ARCH LM-test; Null hypothesis: no ARCH

effects

data: coredata(corn_f)

Chi-squared $=3333, \mathrm{df}=12, \mathrm{p}$-value $<2.2 \mathrm{e}-16$

The LM test sets the null hypothesis with the claim that there is no ARCH effect among the data. The null hypothesis is rejected since the $\mathrm{p}$ - value is much lower form the significance level $\alpha=0.05$. So, once again it has been proved that the ARCH effect is present. In other words, it is clearly evident that the volatility $\mathrm{ARCH}$ is present in this data. Since it has been confirmed that ARCH model is present in the data, for modelling volatility one of the ARCH family models can be used to model the volatility. In this paper this will be the Generalized Autoregressive Conditional Heteroscedasticity (GARCH $(p, q))$. The $p$ value is referred to the use of prior returns, whereas the $q$ values are referred to the use of the prior variances. For modelling volatility using this model,
$\mathrm{R}$ provides a package called "rugarch" which will make it much easier to do so. It offers different possibilities of the GARCH model, including specification, estimation, back test, and forecasting. These steps will be conducted for this very data set accordingly.

The first step to be conducted is the specification. The specification determines what kind of GARCH model should be used.

Table 7: GARCH model specification

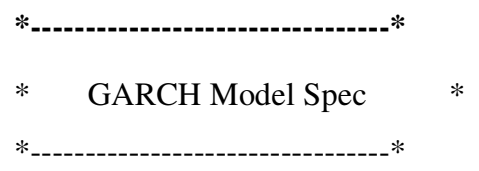

Conditional Variance Dynamics

GARCH Model : $\operatorname{sGARCH}(1,1)$

Variance Targeting : FALSE

Conditional Mean Dynamics

$\begin{array}{ll}\text { Mean Model } & : \text { ARFIMA }(1,0,1) \\ \text { Include Mean } & : \text { TRUE } \\ \text { GARCH-in-Mean } & : \text { FALSE }\end{array}$

Conditional Distribution

$\begin{array}{ll}\text { Distribution } & \text { : norm } \\ \text { Includes Skew } & : \text { FALSE } \\ \text { Includes Shape } & : \text { FALSE } \\ \text { Includes Lambda } & : \text { FALSE }\end{array}$

This specification has defined the what kind of GARCH model is desirable. The model defined in the specification is GARHC $(1,1)$, which means that the returns of 1 previous periods, and volatilities of 1 previous periods are observed. The mean is about the expected value, and therefore the armaORder has been set to be $(0,0)$. The reason for choosing this model is because of its simplicity.

The next step is the estimation step. It is a process to find coefficients, and Maximum Likelihood is the approach used for that. 
53J. Karabegović/ Southeast Europe Journal of Soft Computing Vol.7 No.2 September 2018 (44-59)

Table 8: GARCH Estimation Model

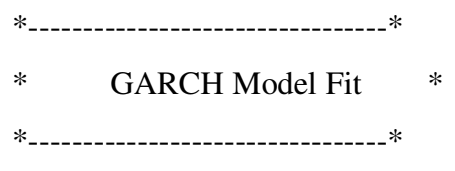

Conditional Variance Dynamics

$\begin{array}{ll}\text { GARCH Model } & : \operatorname{sGARCH}(1,1) \\ \text { Mean Model } & : \operatorname{ARFIMA}(1,0,1) \\ \text { Distribution } & : \text { norm }\end{array}$

Optimal Parameters

Estimate Std. Error $\mathrm{t}$ value $\operatorname{Pr}(>|\mathrm{t}|)$

$\begin{array}{lccccc}\text { mu } & 292.295659 & 0.025993 & 11245.2 & 0 \\ \text { ar1 } & 0.995621 & 0.000267 & 3730.4 & 0 \\ \text { ma1 } & 0.025761 & 0.000002 & 13212.5 & 0 \\ \text { omega } & 0.120890 & 0.000009 & 13904.2 & 0 \\ \text { alpha1 } & 0.033051 & 0.000009 & 3563.4 & 0 \\ \text { beta1 } & 0.964185 & 0.000155 & 6204.5 & 0\end{array}$

From the table above, it can be seen that in the first part it is shown which GARCH model is used. In this case the GARCH $(1,1)$ model has been used, because it is the simplest one. The mean chosen is ARMA $(0,0,0)$ and the distribution is assumed to be normal. The parameters that will be observed for this analysis are the Optimal Parameters. From the Table 8, the following equation is derived:

$$
\sigma_{\mathrm{t}}^{2}=0.120890+0.033051 * \mathrm{x}_{\mathrm{t}-1}{ }^{2}+0.964185 * \sigma_{\mathrm{t}-1}^{2}
$$

The next step is back testing. The back testing is to determine the performance of the model, or in other words how the model has been with respect to the past data. So, basically we are looking for using the past data where we have the equals, and now we get predicted values based on Equation (28). Since Value at Risk (VaR) is the measure of the risk returns, it is assumed that in this paper it will be $1 \%$. If the return is less than the VaR, it is an exception. Therefore, the function used for the back testing is ugarchroll. The report obtained for the back testing is shown in Table 9:
Table 9: VaR Backtest Report

\begin{tabular}{|c|c|c|}
\hline $\begin{array}{l}\text { Model: } \\
\text { norm }\end{array}$ & & sGARCH- \\
\hline Backtest Length: & 3285 & \\
\hline Data: & & \\
\hline
\end{tabular}

alpha:

$1 \%$

Expected Exceed: $\quad 32.9$

Actual VaR Exceed: 157

Actual \%: $\quad 4.8 \%$

Unconditional Coverage (Kupiec)

Null-Hypothesis: Correct Exceedances

LR.uc Statistic: $\quad$ Inf

LR.uc Critical: $\quad 6.635$

LR.uc p-value: $\quad 0$

Reject Null: $\quad$ YES

Conditional Coverage (Christoffersen)

Null-Hypothesis: Correct Exceedances and

$$
\text { Independence of Failures }
$$

LR.cc Statistic: Inf

LR.cc Critical: $\quad 9.21$

LR.cc p-value: $\quad 0$

Reject Null: $\quad$ YES

The table shows that the model used is the standard GARCH model with the assumption to be normally distributed. The length of the back test is 3285 observations, and alpha $=0.01$. The expected exceedance is 33 , but the actual exceedance is 157 . In other words, it is $4.8 \%$ and it is way up than the $1 \%$, so the idea of correct exceedance is rejected. As it can be seen in the table, there are two tests the Kupiec and Christoffersen tests. Their hypotheses are that there are correct number of exceedances. Since the $\mathrm{p}-$ value in both cases is lower than 0.01 , the hypotheses are rejected. 
54J. Karabegović/ Southeast Europe Journal of Soft Computing Vol.7 No.2 September 2018 (44-59)

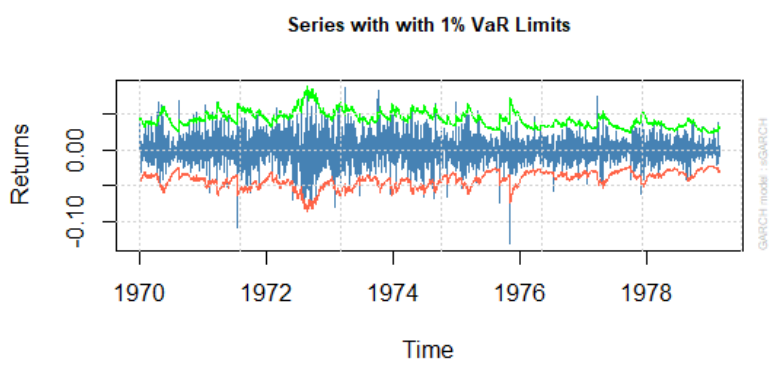

Figure 2: VaR Limits

From the Figure above, the blue part represents the prices or returns. The red line represents the $\mathrm{VaR}$ at $1 \%$, and the blue part is allowed to cross the red line 33 times. However, it crossed the line 157 times.

After the model has been back tested, the forecast can be pursued. With the help of ugarchforecast, it was possible to forecast as many periods ahead as I wanted to choose. The forecast for the next thirty days I obtained as it follows in Table 10:

Table 10: GARCH Model Forecast

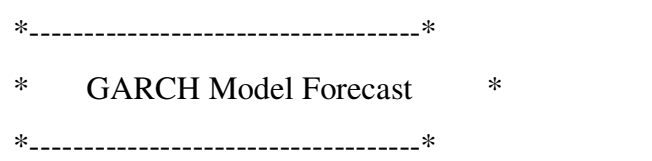

Model: sGARCH

Horizon: 30

Roll Steps: 0

Out of Sample: 0

0-roll forecast [T0=1979-02-28 01:00:00]:

$$
\text { Series Sigma }
$$

$\mathrm{T}+1 \quad 6.908 \mathrm{e}-04 \quad 0.01258$

$\mathrm{T}+2-1.836 \mathrm{e}-040.01265$

$\mathrm{T}+3 \quad 6.240 \mathrm{e}-040.01273$

$\mathrm{T}+4-1.219 \mathrm{e}-040.01280$

$\mathrm{T}+5 \quad 5.670 \mathrm{e}-040.01287$

T+6 -6.927e-05 0.01294

$\mathrm{T}+7 \quad 5.184 \mathrm{e}-040.01301$

$\mathrm{T}+8 \quad-2.436 \mathrm{e}-050.01308$
T+9 4.769e-04 0.01315

$\mathrm{T}+10 \quad 1.394 \mathrm{e}-05 \quad 0.01322$

$\mathrm{T}+11 \quad 4.415 \mathrm{e}-040.01328$

$\mathrm{T}+12$ 4.662e-05 0.01335

$\mathrm{T}+13 \quad 4.114 \mathrm{e}-040.01341$

$\mathrm{T}+147.449 \mathrm{e}-050.01348$

$\mathrm{T}+15$ 3.856e-04 0.01354

$\mathrm{T}+16 \quad 9.826 \mathrm{e}-050.01360$

$\mathrm{T}+17 \quad 3.637 \mathrm{e}-040.01366$

$\mathrm{T}+18 \quad 1.185 \mathrm{e}-040.01372$

$\mathrm{T}+19 \quad 3.449 \mathrm{e}-040.01378$

$\mathrm{T}+20 \quad 1.358 \mathrm{e}-040.01384$

T+21 3.290e-04 0.01390

$\mathrm{T}+22 \quad 1.506 \mathrm{e}-040.01395$

$\mathrm{T}+23$ 3.153e-04 0.01401

$\mathrm{T}+24 \quad 1.632 \mathrm{e}-040.01407$

$\mathrm{T}+25 \quad 3.037 \mathrm{e}-040.01412$

$\mathrm{T}+26 \quad 1.739 \mathrm{e}-040.01418$

$\mathrm{T}+27 \quad 2.938 \mathrm{e}-040.01423$

$\mathrm{T}+28 \quad 1.831 \mathrm{e}-040.01428$

T+29 2.853e-04 0.01433

$\mathrm{T}+30 \quad 1.909 \mathrm{e}-040.01439$

The column Series represents the expected volatility for the next thirty days, whereas the expected risk is in the Sigma column. It is also possible to estimate the VaR from the forecasted data. It is done by determining the $99 \%$ quantile which is 2.326348. This number multiplied with the standard deviation gives the VaR for one estimated period (each estimated Sigma is estimated for a certain predicted period).

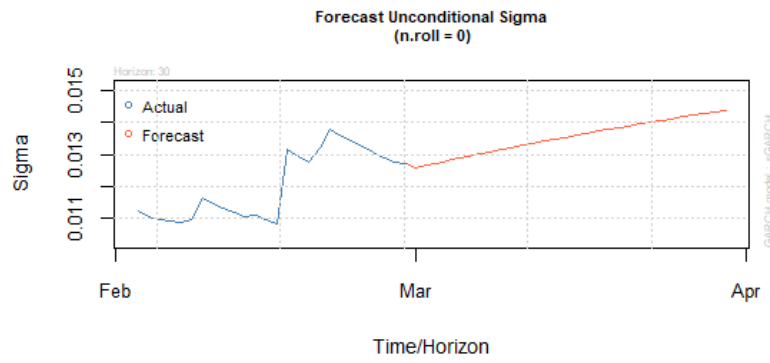


55J. Karabegović/ Southeast Europe Journal of Soft Computing Vol.7 No.2 September 2018 (44-59)

Figure 3: Forecasted Sigma Values

The analysis is continuing with the soya futures data. As for the corn futures data, the soya futures data is also obtained for the period from 03/01/2005. It has been processed in the same manner as the data for the corns. Firstly, the plot will be provided. With the plot the trends of futures prices can be determined. The plot is provided in Figure 4. From the figure it can be seen which periods are characterized with high volatilities, which is almost the same as in the case of corn futures.

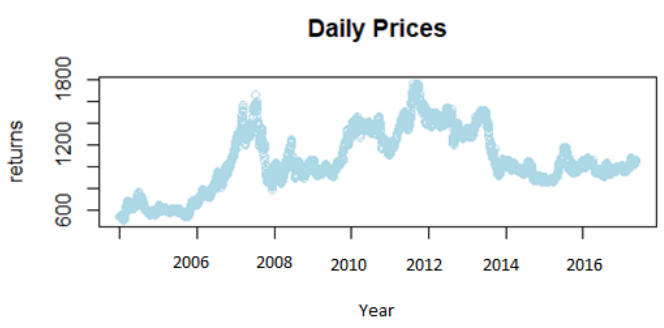

Figure 4: Forecasted Sigma Values

As it is noticed for corn data, the futures prices are jumping in 2006, fluctuate until 2013, and again start moving rapidly. In the periods after the crisis, the prices have a normal level. In order to conduct the GARCH volatility modelling, the first thing to is to test whether the ARCH effect is present. From Table 11, the Ljung - Box test rejects the null hypothesis, with its p-value lower than the significance level of 0.05 and the volatility is heteroscedastic.

Table 11: Ljung - Box Test

Box-Ljung test

data: as.double(unlist(soyaa1))

$\mathrm{X}$-squared $=284240, \mathrm{df}=360, \mathrm{p}$-value $<2.2 \mathrm{e}-16$

Running the LM - test the same results have been obtained. The LM - test rejected its own null hypothesis with is $\mathrm{p}$ - value much lower than the significance level of 0.05 .

\section{Table 12:LM Test}

ARCH LM-test; Null hypothesis: no ARCH effects

data: coredata $(\mathrm{d} 1)$

Chi-squared $=142.06, \mathrm{df}=12, \mathrm{p}$-value $<2.2 \mathrm{e}-16$ since the presence of the ARCH effect has been confirmed, the next step in the analysis of Soya Futures data is to specify the GARCH model. From the Table 13, the model specification can be read.

Table 13: GARCH Model Speculation

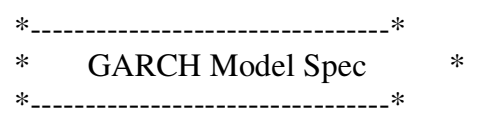

Conditional Variance Dynamics

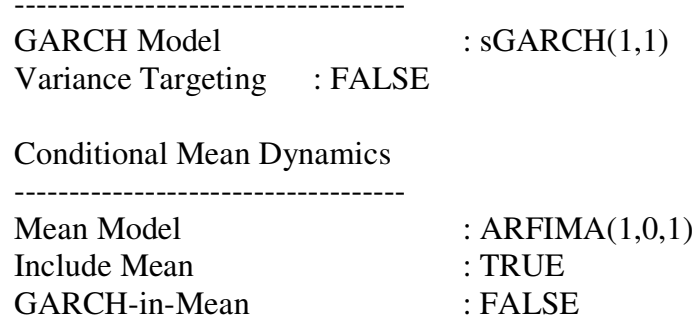

Conditional Distribution

$\begin{array}{ll}\text { Distribution } & \text { : norm } \\ \text { Includes Skew } & \text { : FALSE } \\ \text { Includes Shape } & : \text { FALSE } \\ \text { Includes Lambda } & : \text { FALSE }\end{array}$

Again, GARCH $(1,1)$ has been chosen because of its simplicity. The step that follows is related to the model estimation used to find the coefficients with the help of the Maximum Likelihood method. Table 14 will provide more information regarding this:

Table 14: GARCH Model Fit

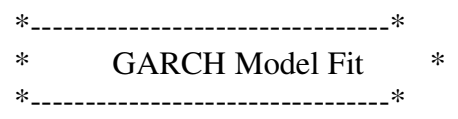

Conditional Variance Dynamics

$\begin{array}{ll}\text { GARCH Model } & : \operatorname{sGARCH}(1,1) \\ \text { Mean Model } & : \operatorname{ARFIMA}(1,0,1) \\ \text { Distribution } & : \text { norm }\end{array}$

Optimal Parameters

Estimate Std. Error $\mathrm{t}$ value $\operatorname{Pr}(>|\mathrm{t}|)$

$\mathrm{mu} \quad 1.3447 \mathrm{e}+03 \quad 2.0162 \mathrm{e}+01 \quad 66.69180 .000000$

ar1 $\quad 6.3880 \mathrm{e}-01 \quad 7.6160 \mathrm{e}-03 \quad 83.87300 .000000$ 
56J. Karabegović/ Southeast Europe Journal of Soft Computing Vol.7 No.2 September 2018 (44-59)

ma1 $\quad 3.1671 \mathrm{e}-02 \quad 1.2813 \mathrm{e}-02 \quad 2.47190 .013441$

omega $2.0948 \mathrm{e}+04 \quad 1.3926 \mathrm{e}+03 \quad 15.04240 .000000$

alpha1 $9.9753 \mathrm{e}-01 \quad 2.6312 \mathrm{e}-02 \quad 37.91230 .000000$

beta1 $1.4690 \mathrm{e}-03 \quad 1.2170 \mathrm{e}-03 \quad 1.20720 .227349$

The first part of the table determines which GARCH model is used, and it can be seen that it is the GARCH $(1,1)$ model. The optimal parameters are actually the coefficients for the formation of the GARCH $(1,1)$ equation:

$03 * \sigma_{\mathrm{t}-1}^{2} \quad \sigma_{\mathrm{t}}^{2}=0948 \mathrm{e}+04+9.9753 \mathrm{e}-01 * \mathrm{x}_{\mathrm{t}-1}^{2}+1.4690 \mathrm{e}-$

The analysis will proceed with the Back Testing conducted. For the back testing, again the tool from the package "rugarch" will be used. In this case, $1 \% \mathrm{VaR}$ will also be used for testing the performance of the model with respect to the past data.

Table 15: VaR Backtest Report

VaR Backtest Report

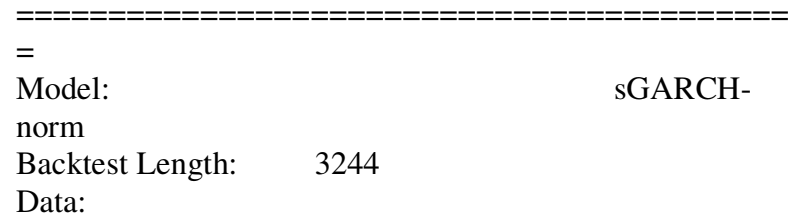

\begin{tabular}{|c|c|}
\hline alpha: & $1 \%$ \\
\hline Expected Exceed: & 32.4 \\
\hline Actual VaR Exceed: & 155 \\
\hline Actual \%: & $4.8 \%$ \\
\hline \multicolumn{2}{|c|}{ Unconditional Coverage (Kupiec) } \\
\hline Null-Hypothesis: & Correct Exceedances \\
\hline LR.uc Statistic: & 243.654 \\
\hline LR.uc Critical: & 6.635 \\
\hline LR.uc p-value: & 0 \\
\hline Reject Null: & YES \\
\hline \multicolumn{2}{|c|}{ Conditional Coverage (Christoffersen) } \\
\hline Null-Hypothesis: & Correct Exceedances and \\
\hline \multicolumn{2}{|c|}{ Independence of Failures } \\
\hline LR.cc Statistic: & 259.221 \\
\hline LR.cc Critical: & 9.21 \\
\hline LR.cc p-value: & 0 \\
\hline Reject Null: & YES \\
\hline
\end{tabular}

The results in the table show that the GARCH $(1,1)$ model is assumed to be normally distributed and comprised of 3244 observations. The alpha $=0.01$. The expected exceedance is 33 , but the actual exceedance is 155 . In other words, it is $4.8 \%$ and it is way up than the $1 \%$, so the idea of correct exceedance is rejected. Both Kupiec and Christoffersen tests have significantly lower $\mathrm{p}$ - value than the alpha which equals 0.01 . Figure 5 depicts the $\mathrm{VaR}$ at $1 \%$.

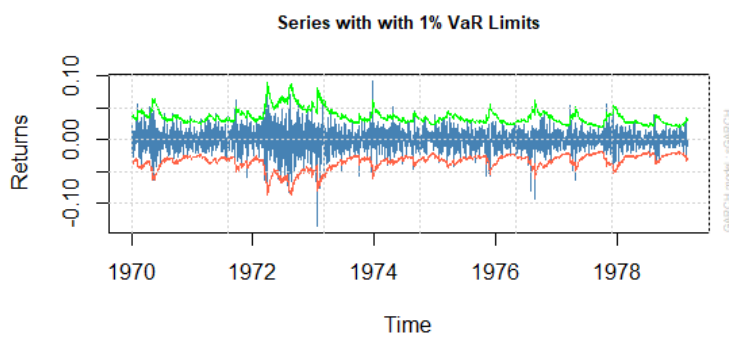

Figure 5: Series with 1\% VaR limits

The red line on the graph represents the $1 \% \mathrm{VaR}$. The back-test shows that the returns marked with the blue colour should are allowed to cross the red line 33 times, however, this happened 155 times. The final step is the forecast part. Again, a tool from the ugarch family will be used, namely the ugarchforecast function. With the help of this function, the forecasts for the upcoming thirty periods have been predicted. It is shown in Table 16:

\section{Table 16: GARCH Model Forecast}

Series Sigma

$\mathrm{T}+1 \quad 0.00020870 .01307$

$\mathrm{T}+2 \quad 0.00022660 .01310$

$\mathrm{T}+3 \quad 0.00023480 .01313$

$\mathrm{T}+40.00023860 .01316$

$\mathrm{T}+5 \quad 0.00024040 .01319$

$\mathrm{T}+6 \quad 0.00024120 .01322$

$\mathrm{T}+7 \quad 0.00024160 .01325$

$\mathrm{T}+8 \quad 0.00024180 .01328$

$\mathrm{T}+90.00024190 .01331$

$\mathrm{T}+100.00024190 .01334$

$\mathrm{T}+110.00024190 .01337$

$\mathrm{T}+120.00024190 .01340$

$\mathrm{T}+130.00024190 .01342$

$\mathrm{T}+140.00024190 .01345$

$\mathrm{T}+150.00024190 .01348$

$\mathrm{T}+160.00024190 .01351$

$\mathrm{T}+170.00024190 .01353$

$\mathrm{T}+180.00024190 .01356$

$\mathrm{T}+190.00024190 .01359$ 
$\mathrm{T}+200.00024190 .01361$

$\mathrm{T}+210.00024190 .01364$

$\mathrm{T}+220.00024190 .01367$

$\mathrm{T}+230.00024190 .01369$

$\mathrm{T}+240.00024190 .01372$

$\mathrm{T}+250.00024190 .01374$

$\mathrm{T}+260.00024190 .01377$

$\mathrm{T}+270.00024190 .01379$

$\mathrm{T}+280.00024190 .01382$

$\mathrm{T}+290.00024190 .01384$

$\mathrm{T}+300.00024190 .01386$

As for the corn futures prices, the column Series represents the expected volatility for the next thirty days, whereas the expected risk is in the Sigma column. Determining 99\% quantile which is 2.326348 , and multiplying it with the predicted standard deviation (for each predicted period separately), the future volatility is obtained.In Figure 6 the volatility forecast is graphically represented:

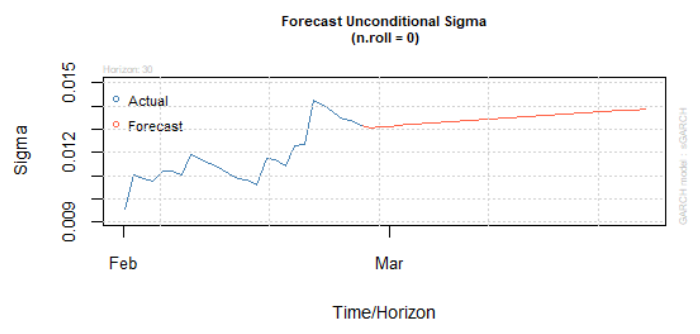

Figure 6: Volatility Forecast

The implied volatility model is deriving the volatility from an option pricing model in which we are familiar with the price of the option. Black - Scholes Model is a function of the underlying asset's price, risk-free rate, volatility, the strike price, risk-free rate, and time to maturity. In the implied volatility procedure, the aim is to calculate the volatility or sigma, as it is denoted in the formula. The RScript attached in the appendix shows clear procedure of computing the implied volatility. Implied volatility represents the theoretical volatility of the Black-Scholes model which has to be calculated with the help of a numerical process, in my case, the Newton - Raphson model. The Newton- Raphson method is an algorithm for finding the roots of the potential solution. It starts with an initial guess. Vega tells in what direction the price will move if there is $1 \%$ change in volatility.

Values that are compared are the model values, which represent the values of an option calculated using the implied volatilities derived from the Black - Scholes formula, and the actual options prices, or the market values as shown in tables 17 and 18 , respectively.
Using the RStudio package "fOptions", the implied volatility has been calculated, firstly for corn, and then for soya. The results are shown in Table 17 and 18 for Corn and Soya option in Appendix, respectively.

From the Table 17, it can be seen that the model values and the market values are quite accurate. The same procedure has been done for the soya products. Looking at Table 18 and comparing the model values to the market values, the same conclusion can be derived as for the corn options.

Since the aim of the paper is to compare the models and to see which model is better performing one, another test for comparison has been conducted. The models used is the forecast regression model. For the GARCH $(1,1)$ model, the forecasted volatility was the dependant variable, whereas the realized volatility was the independent variable. Table 19 in Appendix shows that the Adjusted $\mathrm{R}^{2}$ for GARCH $(1,1)$ equals 0.2469 , whereas Table 20 shows that this variable is equal to 0.3273 for soya options. Running the regression to examine the relationship between the realized volatility relative to the implied volatility, the results from tables 21 and 22 indicate that Adjusted $\mathrm{R}^{2}$ is 0.0754 and 0.06636 respectively. These indicators show that the implied volatility models explain the realized volatility even less than the volatility forecasted with the help of GARCH $(1,1)$. If the conclusion is attempted to be derived from the $\mathrm{p}$ - value in comparison with the value at risk of $1 \%$, then only GARCH $(1,1)$ model for soya products is statistically significant.

\section{CONCLUSION}

Price risk management was present even in 1700 s, where the probability theory has been applied. After the World War II, risk management became a hot topic among the researchers. Risk management was usually linked to the insurances to protect the individuals from adverse events. However, after 1950s, financial derivatives as instruments for hedging the risk have been introduced. This thesis has been concerned with observing the agricultural commodity markets and hedging the risk with the help of futures and options. Options are financial derivatives that derive their value based on the underlying assets. The options give the buyer certain rights, but not the obligations, whereas the seller has the obligations needed to be fulfilled. A special case of options is options on futures. Options on futures are most common for agricultural commodities, and these options are usually the American options. Data that has been processed with the help of RStudio and its customized packages is obtained from CBOT and CME. The futures data for soya and corn has been obtained for period from 01/01/2005 until 01/04/2018, and the frequency of the data is daily. The options on futures data for corn and soya has a time interval between 01/01/2013 
till 01/04/2018, and it has monthly frequency. Models used for modeling the volatility are the GARCH $(1,1)$ model and the Black - Scholes Implied volatility model. The aim of this thesis was to determine the accuracy of these models and to assess and compare their predictive powers. It is important to mention that several limitations for conducting the study might have biased the results. These limitations are data access. The $\operatorname{GARCH}(1,1)$ model analyzed daily data, whereas the implied volatility model has used the monthly data. By analyzing the models and comparing them with the help of Adjusted $\mathrm{R}^{2}$, the conclusions that have been derived are that the GARCH $(1,1)$ model has shown higher values for the indicator than the Implied Volatility Model. Even these results are consistent with the work conducted by other authors, the low value of the Adjusted $\mathrm{R}^{2}$ do not imply any confident conclusion regarding the model performances.

Hopefully, this work will be extended in my future research. I am planning on extending this work by including additional tests for comparison of models, or even to introduce a model that is more accurate for the American options, such as Binomial Trees model. Besides, the data might be analyzed by excluding the assumption that the options will be exercised at their expiration date.

\section{BIBLIOGRAPHY}

A., P. (Safeguarding food security in volatile global markets). Why volatility matters. Rome: FAO.

Shinde, A.S. , and Takale, K.C. (2012). Study of Black Scholes Model and its Applications. International Conference on Modelling, Optimisation and Computing, (pp. 1-3).

Trianfyllou, A. G. D. (2013). Volatility Forecasting in Agricultural Commodity Markets. 5-7.

Black, F., \& Scholes, M. (1973). The Pricing of Options and Corporate Liabilities. The Journal of Political Economy, 637-654.

Bollerslev, T. (1986). Generalized Autoregressive Conditional Heteroskedasticity. Journal of Econometrics, $1-2$.

Canina, L., \& Figlewski, S. (1993). The Informational Content of Implied Volatility. The Review of Financial Studies, 659-681.

Canina, L., \& Figlewski, S. (1993). The Informtional Content of Implied Volatility. The Review of Financial Studies , 659-662.

Cohen, G. (2005). The Four Basic Options Strategies. In The Bible of Options Strategies : The Definitive Guide for Practical Trading Strategies (pp. 1-5).
Cox, J., Ross, S., \& Rubinstein, M. (1979). Option pricing: A simple approach. Journal of Financial Economics, 229263.

Cui, Y., Rollin, S. d., \& Germano, G. (2016, December 6). Retrieved from https://arxiv.org/pdf/1612.01951.pdf

Dharmawan, K. (2017). Pricing European Options on Agriculuture Commodity Prices Using Mean-Reversion Model with Jump Diffusion.

Dumas, B., Fleming, J., \& Whaley, R. E. (1998). Implied Volatility Functions: Empirical Tests. The Journal of Finance, 2059 - 2104.

Futures Contracts. (2011). In S. Janakiraman, Derivatives and Risk Management (pp. 77 - 87).

Garcia, R. C., Contreras, J., Akkeren, M. v., \& Garcia, J. B. (2005). A GARCH Forecasting Model to Predict DayAhead Electricity Prices. IEEE Transactions on Power Systems.

Garcia, R. C., Contreras, J., Member, S., IEEE, Akkeren, M. v., \& Garcia, J. B. (2005). A GARCH Forecasting Model to Predict Day-Ahead Electricity Prices. IEEE transactions on Power Systems, 867 - 874,.

Gilbert, C., \& Morgan, C. (2010). Food price volatility.

Gitman, L. J., \& Joehnk, M. D. (2008). Chapter 14: Derivatives Securities. In L. J. Gitman, \& M. D. Joehnk, Fundamentals of Investing (pp. 610-640).

Gitman, L. J., \& Joehnk, M. D. (2008). Commodities and Financial Futures. In L. J. Gitman, \& M. D. Joehnk, Fundamentals of Investing. Greg Tobin.

Gitman, L. J., \& Joehnk, M. D. (2008). Options: Put and Calls . In Fundamentals of Investing (pp. 614 - 615).

Hull, J. (2008). Estimating Volatilities and Correlations. In J. Hull, Options, Futures, and Other Derivatives (pp. 502$510)$.

Lien, G. (2002). Term Structure of Volatility and Price Jumpus in Agricultural Markets - Evidence from Optional Data. Exploring Diversity in the European Agri- Food System, (pp. 2-6,).

Posedel, P. (2005) Properties and Estimation of GARCH $(1,1)$ Model. Metodološki zvezki, Vol. 2, No. 2, 243-257

Anderson, R.W. (1985). Some dtereminants of the volatility of futures prices. Journal of Futures Markets, 331-348.

Reider, R. (2009, October 19). Volatility Forecasting I: GARCH Models.

Time Series Econometrics: Forecasting. (2004). In D. N. Gujarati, Basic Econometrics (Fourth ed., pp. 856-862). 
59J. Karabegović/ Southeast Europe Journal of Soft Computing Vol.7 No.2 September 2018 (44-59)

Triantafyllou, A., Dotsis, G., \& Sarris, A. H. (2013, 12

17). Volatility Forecasting in Agricultural Commodity

Markets.

W., G., \& R.W., K. (1996). Futures prices and the maturity effects. Journal of Futures Markets, 809-828.

Yalincak, O. H. (2012). Criticism of the Black-Scholes Model:But Why is It Still Used? Retrieved from SSRN:

https://papers.ssrn.com/sol3/papers.cfm?abstract_id=2115

141

Ypma, T. J. (1995). Historical Development Of The Newton-Raphson Method. Society for Industrial and Applied Mathematics, 37, 531-551. 